ARTICLE

\title{
Interface chemistry of an amide electrolyte for highly reversible lithium metal batteries
}

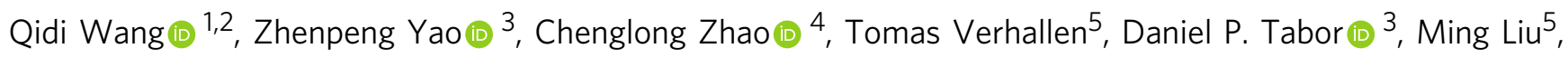
Frans Ooms ${ }^{5}$, Feiyu Kang ${ }^{1,2}$, Alán Aspuru-Guzik (i) ${ }^{3,6}$, Yong-Sheng Hu (1) ${ }^{4}$, Marnix Wagemaker (i) ${ }^{5 凶} \&$ Baohua Li (iD) 1,2网

Metallic lithium is a promising anode to increase the energy density of rechargeable lithium batteries. Despite extensive efforts, detrimental reactivity of lithium metal with electrolytes and uncontrolled dendrite growth remain challenging interconnected issues hindering highly reversible Li-metal batteries. Herein, we report a rationally designed amide-based electrolyte based on the desired interface products. This amide electrolyte achieves a high average Coulombic efficiency during cycling, resulting in an outstanding capacity retention with a $3.5 \mathrm{mAh} \mathrm{cm}{ }^{-2}$ high-mass-loaded $\mathrm{LiNi}_{0.8} \mathrm{Co}_{0.1} \mathrm{Mnn}_{0.1} \mathrm{O}_{2}$ cathode. The interface reactions with the amide electrolyte lead to the predicted solid electrolyte interface species, having favorable properties such as high ionic conductivity and high stability. Operando monitoring the lithium spatial distribution reveals that the highly reversible behavior is related to denser deposition as well as top-down stripping, which decreases the formation of porous deposits and inactive lithium, providing new insights for the development of interface chemistries for metal batteries.

\footnotetext{
${ }^{1}$ Shenzhen Key Laboratory of Power Battery Safety and Shenzhen Geim Graphene Center, Tsinghua Shenzhen International Graduate School, Tsinghua University, Shenzhen 518055, China. ${ }^{2}$ School of Materials Science and Engineering, Tsinghua University, 100084 Beijing, China. ${ }^{3}$ Department of Chemistry and Chemical Biology, Harvard University, Cambridge, MA 02138, USA. ${ }^{4}$ Key Laboratory for Renewable Energy, Beijing Key Laboratory for New Energy Materials and Devices, Beijing National Laboratory for Condensed Matter Physics, Institute of Physics, Chinese Academy of Sciences, 100190 Beijing, China. ${ }^{5}$ Department of Radiation Science and Technology, Delft University of Technology, Mekelweg 15, 2629 JB Delft, The Netherlands. ${ }^{6}$ Department of Chemistry

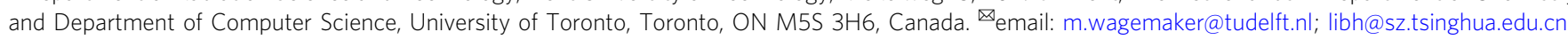


ithium-ion batteries (LIBs) have enabled the progress in portable electronics and automotive applications ${ }^{1,2}$. However, the demand for higher energy density batteries, requires new electrochemical energy storage technologies beyond the current Li-ion insertion chemistries ${ }^{3}$. For decades metallic Li has been considered as promising anode owing to its high specific capacity of $3860 \mathrm{mAh} \mathrm{g}^{-1}$ and low redox potential of $-3.04 \mathrm{~V}$ (vs. the standard hydrogen electrode), providing a more than ten-time larger specific capacity in comparison with the current graphite anode ${ }^{4}$. However, several challenges remain to be addressed before Li-metal batteries can be applied in practice, including the uncontrolled dendrite growth and low Coulombic efficiency, which are responsible for the poor cycling stability and safety hazards ${ }^{5-7}$. The key issue is the high reactivity between metallic $\mathrm{Li}$ and organic liquid electrolytes, producing decomposition species that cover the surface of the electrodes, which is referred to as solid electrolyte interphase $(\mathrm{SEI})^{2,8,9}$. The SEI layer can support the reversible cycling of electrodes by passivating detrimental reactions, however, extensive and uncontrolled SEI growth leads to irreversible electrolyte and electrode degradation reactions. The cycling reversibility, and hence of the battery cycle life depends on the properties of the SEI species. Electrolyte reduction products are often poor ion-conducting inorganic constituents (e.g., $\mathrm{Li}_{2} \mathrm{O}$, $\mathrm{LiF}$, and $\mathrm{Li}_{2} \mathrm{CO}_{3}$ ) and unstable organic constituents (e.g., ROCO ${ }_{2} \mathrm{Li}$ and $\mathrm{ROLi}$, $\mathrm{R}$ representing $-\mathrm{H}, \mathrm{CH}_{3},-\mathrm{CH}_{2} \mathrm{CH}_{3}$, etc.). These species can result in the continuous consumption of both electrolyte and $\mathrm{Li}$ metal, and hinder the reversible Li plating/ stripping by increasing the interface impedance ${ }^{5,6,10,11}$.

A good SEI layer will serve as a physical barrier that blocks further side reactions between metallic $\mathrm{Li}$ and organic liquid electrolytes, where its composition should facilitate dense, uniform and reversible plating/stripping ${ }^{2,8,9}$. The composition of the SEI layer is determined by the electrolyte chemistry, including the selection of salts, solvents, additives and so on ${ }^{12-16}$. To realize the ideal SEI components, having negligible electronic conductivity, a high ionic conductivity and good mechanical/chemical stability, various strategies have been developed ${ }^{12,17-21}$. Highly or locally concentrated electrolytes are used to enhance the electrochemical stability towards $\mathrm{Li}$ metal anodes ${ }^{12,17,18,22}$. Increasing the salt concentration will effectively increase the interactions between cations and anions in the liquid electrolyte environment, and minimize the presence of free-electron-state solvent molecules, thereby reducing decomposition of the solvents. However, the use of high salt concentrations introduces other challenges, such as poor ionic conductivity, high viscosity and high cost, which need to be addressed towards practical applications ${ }^{19,23}$. Highly fluorinated electrolytes, present another promising strategy based on its high stability against both reduction and oxidation in highvoltage systems ${ }^{17,19}$. All-fluorinated electrolytes with high salt concentrations (up to $7 \mathrm{M})^{17}$ and low salt concentration $(1 \mathrm{M})^{19}$ have been investigated, demonstrating improved cycling stability for the $\mathrm{LiNi}_{0.5} \mathrm{Mn}_{1.5} \mathrm{O}_{4}(5 \mathrm{~V})$ and $\mathrm{LiCoPO}_{4}(4.8 \mathrm{~V})$ high-voltage cathodes, respectively. Despite these promising results, the concern is the formation of poor ionic conducting fluoride species, especially inorganic $\mathrm{LiF}^{24}$, that increase the interface impedance at both the anode and the cathode. In addition, many efforts have been devoted to ether-based electrolytes due to their lower reactivity with $\mathrm{Li}$ metal, as compared to carbonate electrolytes. The ester groups typically promote a multi-state decomposition, leading to further reaction and dissolution of the existing SEI components $10,15,20,25-27$. Unfortunately, the limited oxidation stability of ether-based electrolytes $\left(<4 \mathrm{~V}\right.$ vs. $\left.\mathrm{Li}^{+} / \mathrm{Li}\right)$ precludes their application in combination with high-voltage layered $\mathrm{LiCoO}_{2}$ or $\mathrm{Li}(\mathrm{NiCoMn}) \mathrm{O}_{2}$ cathodes ${ }^{19,28}$. Recently, an ether electrolyte with a concentrated $2 \mathrm{M}$ lithium bis(trifluoromethanesulfonyl)imide (LiTFSI) and $2 \mathrm{M}$ lithium difluoro (oxalato)borate (LiDFOB) salts has been reported, demonstrating good interface stability towards a high-voltage $\mathrm{LiNi}_{1 / 3} \mathrm{Mn}_{1 / 3}$ $\mathrm{Co}_{1 / 3} \mathrm{O}_{2}$ cathode and the $\mathrm{Li}$ metal anode ${ }^{18}$. These advances are very promising, yet challenges remain, motivating further electrolyte innovations that promote highly reversible $\mathrm{Li}$ metal batteries and fundamental studies towards the understanding of $\mathrm{Li}^{+}$plating/ stripping behavior and its relation to the interface chemistry.

Herein, we report an electrolyte that demonstrates excelent cycling stability towards both the Li-metal anode and the Ni-rich NCM811 cathode, based on the rational design of the interface chemistry towards highly ion-conductive and stable interface species. Amide compounds, such as $N, N$-dimethylformamide (DMF) and dimethylacetamide (DMA), are similar to carbonate solvents, where the difference is the substitution of the $-\mathrm{OR}_{2}$ ester group with the $-\mathrm{NR}_{2}$ amide group. Compared to the widely used ethylene carbonate (EC) and dimethyl carbonate (DMC) solvents, amide solvents are expected to form less low ion-conductive inorganic constituents, such as $\mathrm{Li}_{2} \mathrm{O}$ and $\mathrm{Li}_{2} \mathrm{CO}_{3}$, due to absence of the ester groups. Amide compounds have been used as additive to increase the chemical stability against reduced superoxide in Li-air batteries ${ }^{29}$, however, systematic exploration of amides as solvents for Li metal batteries not been investigated to date. In this work, a $1 \mathrm{M}$ Lithium bis(trifluoromethanesulfonyl)imide (LiTFSI) in a mixture of 2,2,2-Trifluoro- $N, N$-dimethylacetamide and fluoroethylene carbonate (FDMA: FEC, 1:1 by volume) was prepared to explore its performance in Li-metal batteries. A high Coulombic efficiency of $\sim 99.3 \%$ is achieved for $\mathrm{Li}$ plating and stripping in $\mathrm{Li} \| \mathrm{Cu}$ cells, and stable $\mathrm{Li}$ plating/stripping is also observed during the prolonged cycling of symmetric Li||Li cells. In contrast to the conventional electrolyte system, $1 \mathrm{M} \mathrm{LiPF}_{6}-\mathrm{EC} /$ DMC, the Li stripping occurs at the top of the Li-metal deposit, providing new insights in the prerequisites of highly reversible lithium metal batteries. Excellent cycling stability is demonstrated in full cells with $\mathrm{Ni}$-rich $\mathrm{LiNi}_{0.8} \mathrm{Co}_{0.1} \mathrm{Mn}_{0.1} \mathrm{O}_{2}$ (NCM811) as cathode, having a high-mass loading of $3.5 \mathrm{mAh} \mathrm{cm}^{-2}$. Quantum chemistry calculations and experimental measurements provide detailed insights in the interface chemistry that is responsible for the improved performance of this promising electrolyte.

\section{Results}

Screening of salts and solvents. At the onset of SEI formation, the solvent sheet with $\mathrm{Li}^{+}$will be reduced by the electrons accumulated in the vicinity of Li metal surface, resulting in the SEI components. To control the SEI composition requires that the preferred interface species should have a higher reduction potential as compared to the main solvents, which is equivalent to a higher electron affinity or a lower lowest unoccupied molecular orbital (LUMO) ${ }^{30}$. According to the LUMO energy obtained from density functional theory (DFT) simulations, shown in Fig. 1a and Supplementary Table 1, FDMA exhibits the lowest LUMO among all solvents studied, demonstrating a high electron affinity, which can be expected to decompose first and hence dominate the SEI formation. $\mathrm{LiNO}_{3}$, as a $\mathrm{N}$-donating additive, has been widely used in ether-based electrolytes ${ }^{31-33}$, however, it is practically insoluble in carbonate solvents $\left(<10^{-5} \mathrm{~g} \mathrm{~mL}^{-1}\right)$ making this a challenging strategy for practical application ${ }^{21,34,35}$. Although FDMA has a comparable HOMO-LUMO gap to $\mathrm{LiNO}_{3}, \mathrm{FDMA}$ has the advantage of being highly soluble in both ether and carbonate solvents, providing a more practical route to introduce $\mathrm{N}$-containing components in the SEI. Since FDMA has a relatively high HOMO level, the utilization of FEC as co-solvent with the lowest HOMO level among the widely used solvents is necessary to enhance the high-voltage stability towards the cathode by means of the formation of $\mathrm{LiF}^{17,19}$. Considering the $\mathrm{Li}$ salts, $\mathrm{LiPF}_{6}$ has the advantage of having a large HOMO-LUMO 


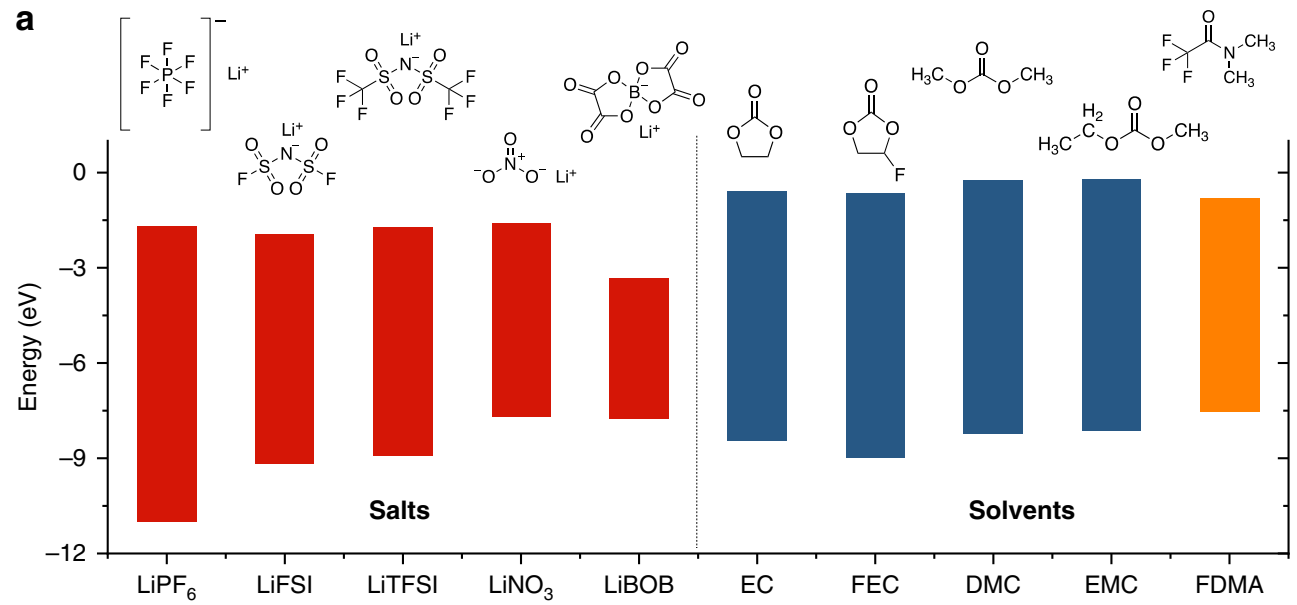

b

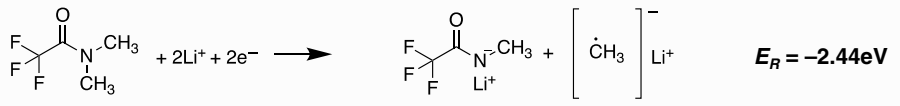

$$
\begin{aligned}
& +6 \mathrm{Li}^{+}+6 \mathrm{e}^{-} \longrightarrow\left[\mathrm{F}_{\mathrm{F}}^{\mathrm{F}} \mathrm{C}_{\mathrm{C}^{\prime}=\mathrm{O}}^{\mathrm{F}}\right]^{-} \mathrm{Li}^{+}+2\left[\dot{\mathrm{C}}_{3}\right]^{-}+\underset{\mathrm{Li}^{+}+\mathrm{Li}^{-} \mathrm{N}^{3+} \cdot \mathrm{Li}^{+}}{\mathrm{L}^{+}} \quad E_{R}=-\mathbf{2 . 7 7 e V}
\end{aligned}
$$

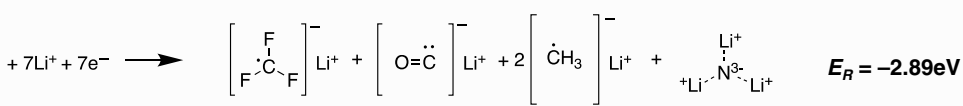

$$
\begin{aligned}
& \mathrm{LiCF}_{3} \quad \mathrm{LiCO} \quad \mathrm{LiCH}_{3} \quad \mathrm{Li}_{3} \mathrm{~N}
\end{aligned}
$$

Fig. 1 Molecular orbital energies and possible decomposition pathways. a Comparison of the highest occupied molecular orbital (HOMO)-lowest unoccupied molecular orbital (LUMO) energy levels for commonly used Li salts and solvents including the 2,2,2-Trifluoro- $N$, N-dimethylacetamide (FDMA). b Possible chemical reactions of FDMA on Li-metal surface according to the reaction energy.

gap, however, FEC is found to be thermally instable in $\mathrm{LiPF}_{6^{-}}$ based electrolytes, which will trigger the generation of unwanted $\mathrm{HF}$ and various acids. These acids will cause significant dissolution of transition metal ions into the electrolytes, and lead to the serious degradation of cathode materials ${ }^{36,37}$. Other frequently used salts, having a similar electrochemical window, are LiTFSI and LiFSI, of which LiTFSI is reported to be more stable towards $\mathrm{Li}$ metal due to the stable $-\mathrm{CF}_{3}$ group ${ }^{38}$. According to the discussion above, we prepared $1 \mathrm{M}$ LiTFSI in a solvent mixture of FDMA/FEC (1:1 by volume) as an electrolyte and explored its properties in Li-metal batteries.

To study the role of the FDMA in the SEI formation, possible decomposition mechanisms of FDMA were considered based on reaction energy calculations. Three reactions, including no $\mathrm{Li}^{+} /$electron attack, single $\mathrm{Li}^{+} /$electron reactions, and two $\mathrm{Li}^{+} /$electron reactions, are considered in combination with the five possible bond-breaking reactions as shown in Supplementary Fig. 1. The thermodynamically most likely first step of the FDMA decomposition is that two $\mathrm{Li}^{+}$and two electrons attack the $\mathrm{N}-\mathrm{CH}_{3}$ bond to form $\mathrm{CH}_{3} \mathrm{Li}$ and a $\mathrm{N}$-containing species. In this amide molecule, the lone pair electron of the amino nitrogen will be conjugated with the $\pi$ electron from the carbonyl group, in which the electron cloud on the nitrogen is less dense and therefore prone to accept an electron. As a result, we propose a possible three-step decomposition mechanism as shown in Fig. $1 \mathrm{~b}$ and Supplementary Fig. 2. It is worth noticing that the decomposition of FDMA will produce $\mathrm{Li}_{3} \mathrm{~N}$ in the second step, and that the final decomposition products are small molecule compounds which are unlikely to undergo further reaction. Furthermore, we calculated the HOMO-LUMO window of DMA and DMF for comparison as shown in Supplementary Fig. 3. The result shows that the introduction of $-\mathrm{CF}_{3}$ group reduces both the
LUMO and HOMO levels, enabling FDMA to participate in the formation of SEI layers at higher potentials. Meanwhile, the stronger electron-withdrawing $-\mathrm{CF}_{3}$ group, as compared to that of $-\mathrm{H}$ and $-\mathrm{CH}_{3}$ groups, generates a repulsive force towards the $\mathrm{C}=\mathrm{O}$ dipole, which contributes to an improved oxidation stability ${ }^{39}$.

Electrochemical stability. Li ||$C u$ cells with different electrolytes were assembled to investigate the Li plating/stripping upon electrochemical cycling as shown in Fig. 2a-c. Clearly, the asprepared amide electrolyte, $1 \mathrm{M}$ LiTFSI-FDMA/FEC (1:1 in volume), exhibits a significantly enhanced Coulombic efficiency and cycling stability as compared to that of the conventional $1 \mathrm{M}$ $\mathrm{LiPF}_{6}-\mathrm{EC} / \mathrm{DMC}$ (1:1 in volume) electrolyte and the reported performance of $1 \mathrm{M} \mathrm{LiPF}_{6}-\mathrm{FEC} / \mathrm{DMC}$ (1:1 in volume) ${ }^{19}$. The average Coulombic efficiency of the Li plating/stripping reaches $\sim 99.3 \%$ for the as-prepared electrolyte up to 100 cycles, which is a major improvement compared to conventional EC-based electrolytes as shown in Fig. 2c. The high reversibility of the Li plating/stripping sets in after several initial cycles, which is competitive to that observed in a concentrated fluorinated electrolyte $(97.7 \% \text { for the first } 100 \text { cycles })^{17}$. The synergy of the components in improving the cycling stability of the as-prepared amide electrolyte is confirmed by comparing the Coulombic efficiency of $\mathrm{Li} \| \mathrm{Cu}$ cells with different solvents and $\mathrm{Li}$ salts, as shown in Supplementary Fig. 4. In addition, the present amide electrolyte generates smaller overpotentials of $\sim 65 \mathrm{mV}$ against the highly fluorinated electrolyte (e.g., $\sim 110 \mathrm{mV}$ in $7 \mathrm{M} \mathrm{LiFSI-}$ FEC) ${ }^{17,19}$. The difference in cycling stability and overpotential is also observed in the symmetric Li-metal cells, especially at higher current densities, see Supplementary Figs. 5-8, where the amide electrolyte exhibits an overpotential of only $\sim 10 \mathrm{mV}$ and $\sim 20 \mathrm{mV}$ 
a

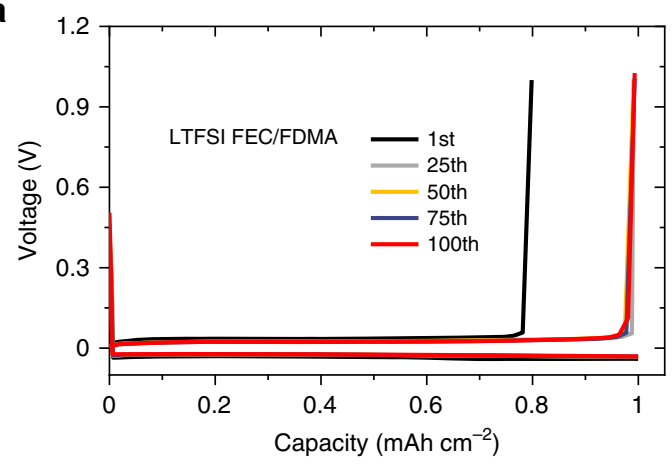

C

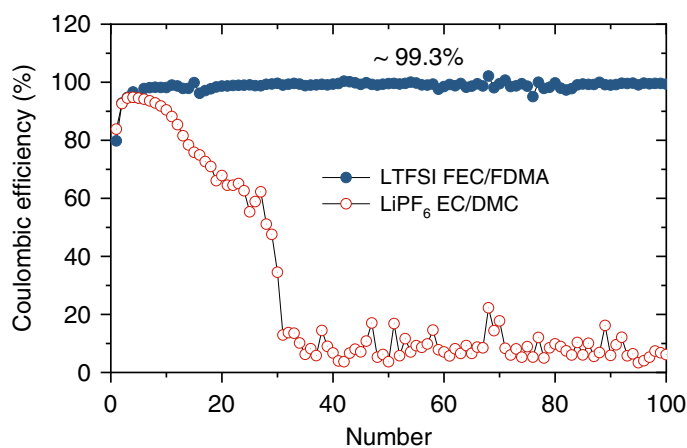

e

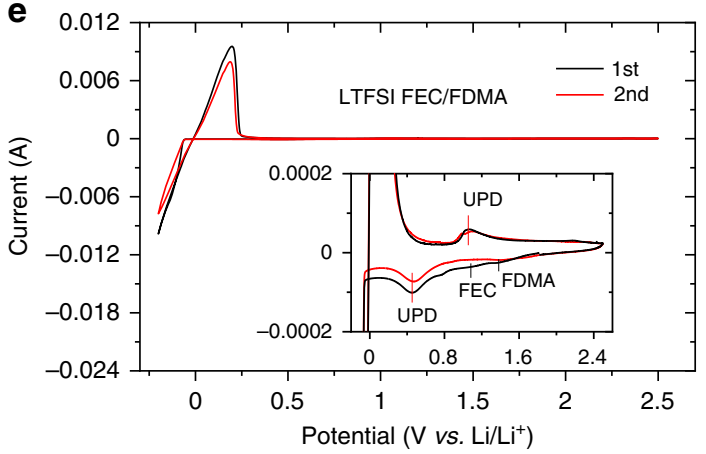

b

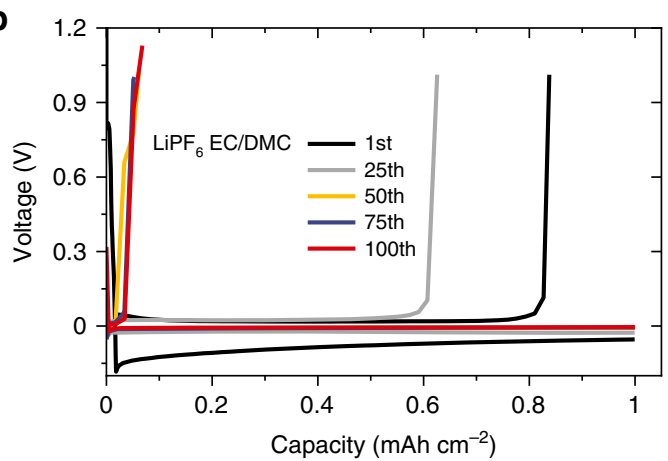

d

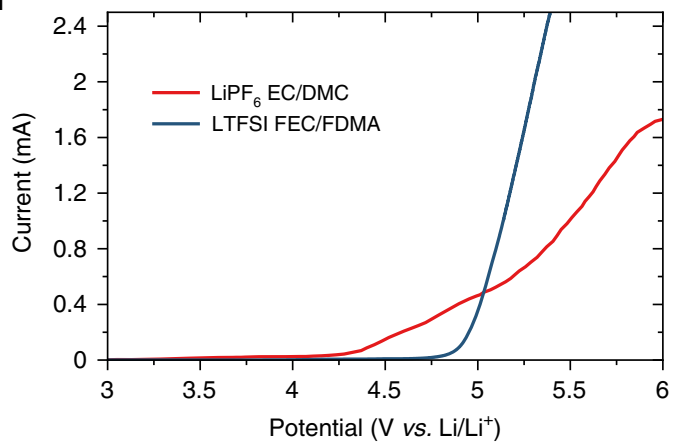

f

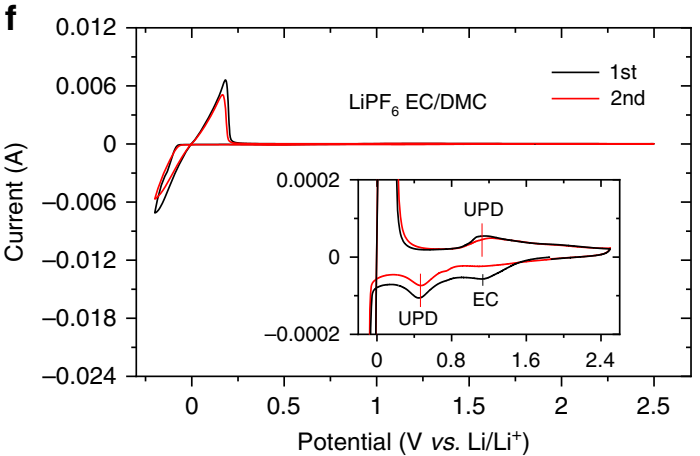

Fig. 2 Electrochemical properties of the electrolytes. a, b Voltage profiles for Li plating/stripping on a Cu working electrode cycled in $1 \mathrm{M}$ LiTFSI-FEC/ FDMA and $1 \mathrm{M} \mathrm{LiPF}_{6}-\mathrm{EC} / \mathrm{DMC}$ at a current density of $1 \mathrm{~mA} \mathrm{~cm}{ }^{-2}$. $\mathbf{c}$ Li plating/stripping Coulombic efficiency in LillCu cells using different electrolytes. Li was electrodeposited at $1 \mathrm{~mA} \mathrm{~cm}{ }^{-2}$ to a total capacity of $1 \mathrm{mAh} \mathrm{cm}-2$ followed by stripping to a cut-off voltage of $1.0 \mathrm{~V}$ vs. Li+/Li. d Positive linear sweep voltammograms (LSV) sweep to gauge the oxidation stabilities of the different electrolytes as evaluated on Lil|stainless-steel cells at a scanning rate of $5 \mathrm{mV} \mathrm{s}^{-1}$. e, $\mathbf{f}$ Cyclic voltammetry (CV) curves of Li\|C cells in $1 \mathrm{M}$ LiTFSI-FEC/FDMA and $1 \mathrm{M} \mathrm{LiPF}_{6}-\mathrm{EC} / \mathrm{DMC}$ electrolytes at a scanning rate of $1 \mathrm{mV} \mathrm{s}^{-1}$. The insets show the enlarged view regions.

at a current density of 1 and $3 \mathrm{~mA} \mathrm{~cm}^{-2}$ for more than 1000 and $900 \mathrm{~h}$, respectively, outperforming the EC-based electrolyte. Furthermore, the cycling stability at a high current density of $5.0 \mathrm{~mA} \mathrm{~cm}^{-2}$, and the rate test from 0.5 to $8 \mathrm{~mA} \mathrm{~cm}^{-2}$ further demonstrate the competitive reaction kinetics of this amide electrolyte (Supplementary Figs. 7 and 8). The high reversibility and remarkable cycling stability of the Li plating/stripping can be attributed to the interface chemistry that leads to a SEI layer in this electrolyte having the desired properties. A noticeable difference is found for the electrolytes after 100 cycles as shown in Supplementary Fig. 9, where the surface of Li metal anode in the EC-based electrolyte turns brown while in the present electrolyte retains its original color. Furthermore, electrochemical impedance spectroscopy is carried out on the $\mathrm{Li} \| \mathrm{Li}$ symmetric cells as shown in Supplementary Fig. 10, where the amide-based electrolyte exhibits a lower electrochemical impedance compared to the EC-based electrolyte, consistent with the above analysis.
The oxidation stability of various electrolytes was evaluated using linear sweep voltammetry (LSV) on Li||stainless-steel cells. The EC-based electrolyte shows a lower oxidation potential, as evidenced by a rapid increase in current above $\sim 4.1 \mathrm{~V}$ as shown in Fig. 2d, while for the present amide-based electrolyte, the oxidation sets in at much higher potential. Cyclic voltammetry (CV) test of $\mathrm{Li} \| \mathrm{Cu}$ cells were performed to study the reductive stability as shown in Fig. 2e, f and Supplementary Fig. 11. It is observed that FDMA has a slightly higher reduction potential than that of EC and FEC. After several initial cycles, the reduction peaks disappear as shown in Supplementary Fig. 12, indicating that FDMA and FEC are only decomposed during the initial cycles.

Evolution of morphology for Li-metal anode. To investigate the Li deposition morphology in different electrolytes, ex situ scanning electron microscopy (SEM) and in situ optical microscopy 
a

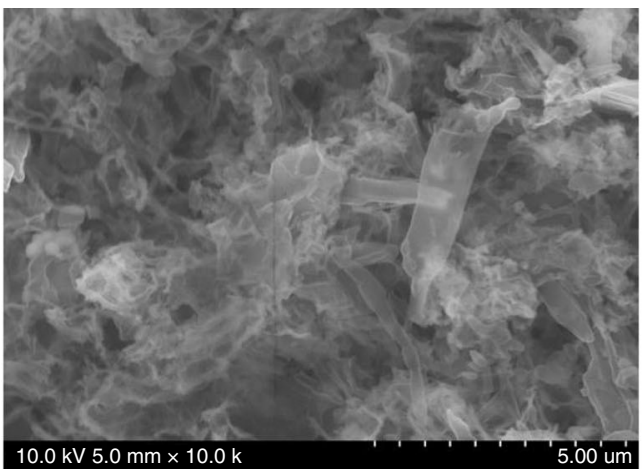

b

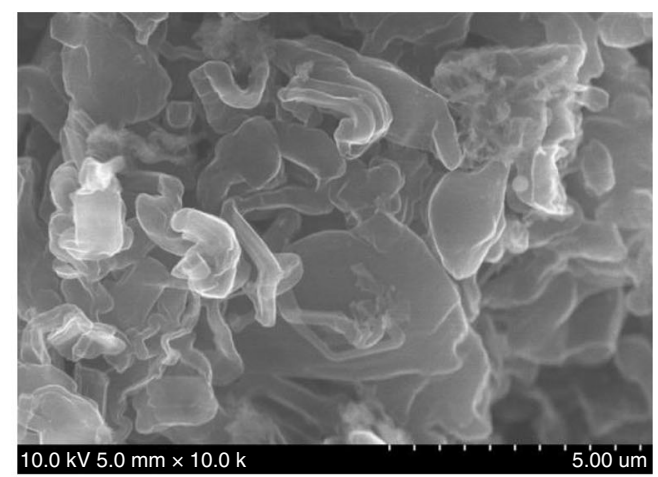

Plating

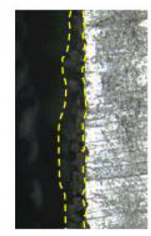

45
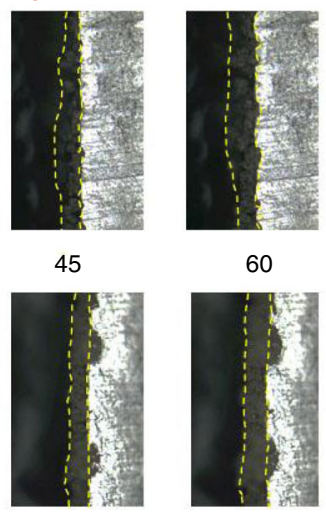

60

Stripping

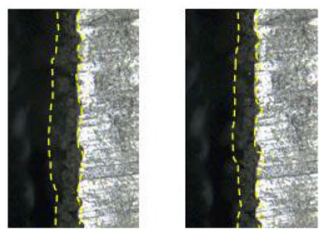

$90 \min$

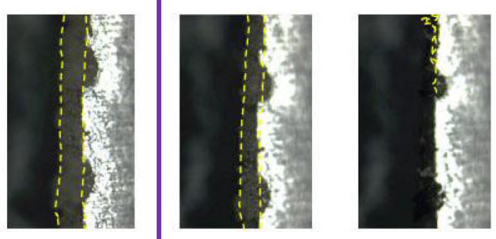

e

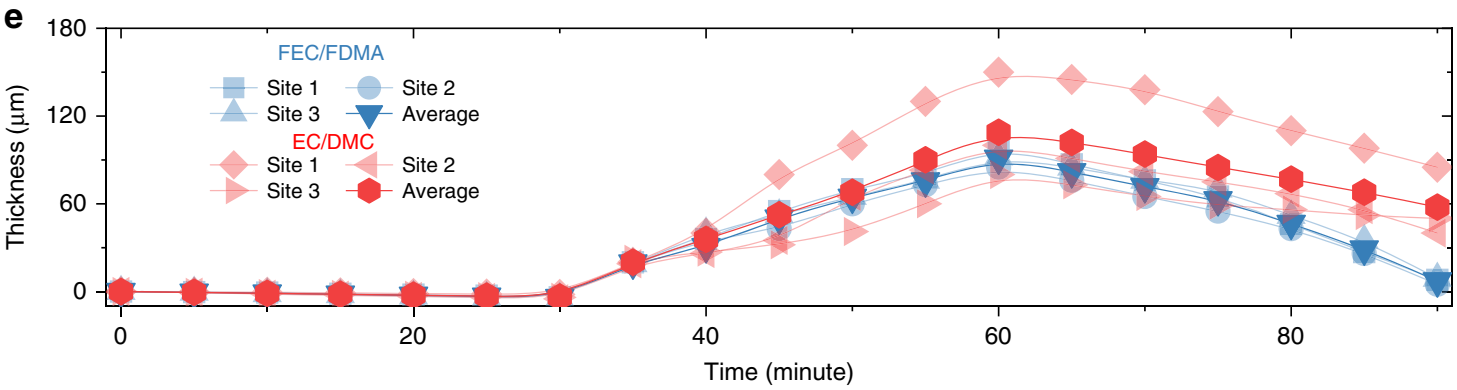

Fig. 3 Characterization of morphology during $\mathbf{L i}^{+}$plating/stripping. a, b Scanning electron microscopy (SEM) images after Li plating at current density of $1 \mathrm{~mA} \mathrm{~cm}^{-2}$ to the capacity of $1 \mathrm{mAh} \mathrm{cm}^{-2}$ on a Cu substrate in $1 \mathrm{M} \mathrm{LiPF}_{6}$-EC/DMC and $1 \mathrm{M}$ LiTFSI-FEC/FDMA. c, d In situ optical microscopy images

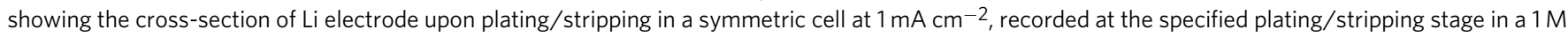
$\mathrm{LiPF}_{6}-\mathrm{EC} / \mathrm{DMC}$ and $1 \mathrm{M}$ LiTFSI-FEC/FDMA electrolytes. The scale bar for $\mathbf{c}, \mathbf{d}$ is $200 \mu \mathrm{m}$. e The evolution of thickness for the deposition of during Li plating/stripping. Three locations, at 1/4, 1/2, and 3/4 along the Li-metal foil are chosen to measure the change in thickness, from which the average thickness is calculated.

are employed, the results of which as shown in Fig. 3a-d. After 100 cycles, the porous structure with needle-like dendritic Li for a few hundred nanometers is observed on the surface of Li metal anode after cycling in the EC-based electrolyte, as shown in Fig. 3a. In contrast, the as-prepared amide-based electrolyte leads to a compact aggregate of granular Li metal particles with sizes in the range of a few microns, as shown in Fig. $3 \mathrm{~b}$. The denser $\mathrm{Li}$ deposition will lead to less exposure of fresh electrolyte to the plated $\mathrm{Li}$ metal, reducing the detrimental decomposition reactions, resulting in a higher cycling stability. Furthermore, a dedicated cell is designed to monitor the Li plating/stripping in real-time, in situ, with an optical microscope. The images in Fig. $3 c$, d are taken at specific stages of cycling for the two different electrolytes and the corresponding movies are provided as Supplementary Movies 1 and 2, respectively. At first, the thickness evolution of the pristine $\mathrm{Li}$ metal was monitored during stripping at $1 \mathrm{mAh} \mathrm{cm}^{-2}$, where a slight decrease is observed for both electrolytes. Upon subsequent Li plating, protrusions appear on the surface of the Li metal electrodes in both electrolyte systems. However, in the EC-based electrolyte, uneven Li deposition is observed resulting in a porous morphology as observed from the side view. In contrast, in the amide electrolyte, a more homogeneous nucleation leads to denser $\mathrm{Li}$ deposition as shown in Fig. 3d. Upon subsequent stripping, almost all the Li deposits disappear in amide electrolyte, whereas a large amount of residual $\mathrm{Li}$ remains on the surface in the presence of the EC-based electrolyte. The corresponding evolution of Li-metal thickness during plating and stripping in both electrolytes, shown in Fig. 3e, confirms the denser and more uniform Li deposition in the amide electrolyte.

Interface between anode and electrolyte. To determine the interface decomposition species, X-ray photoelectron spectroscopy (XPS) analysis is performed on the cycled $\mathrm{Li}$ metal 

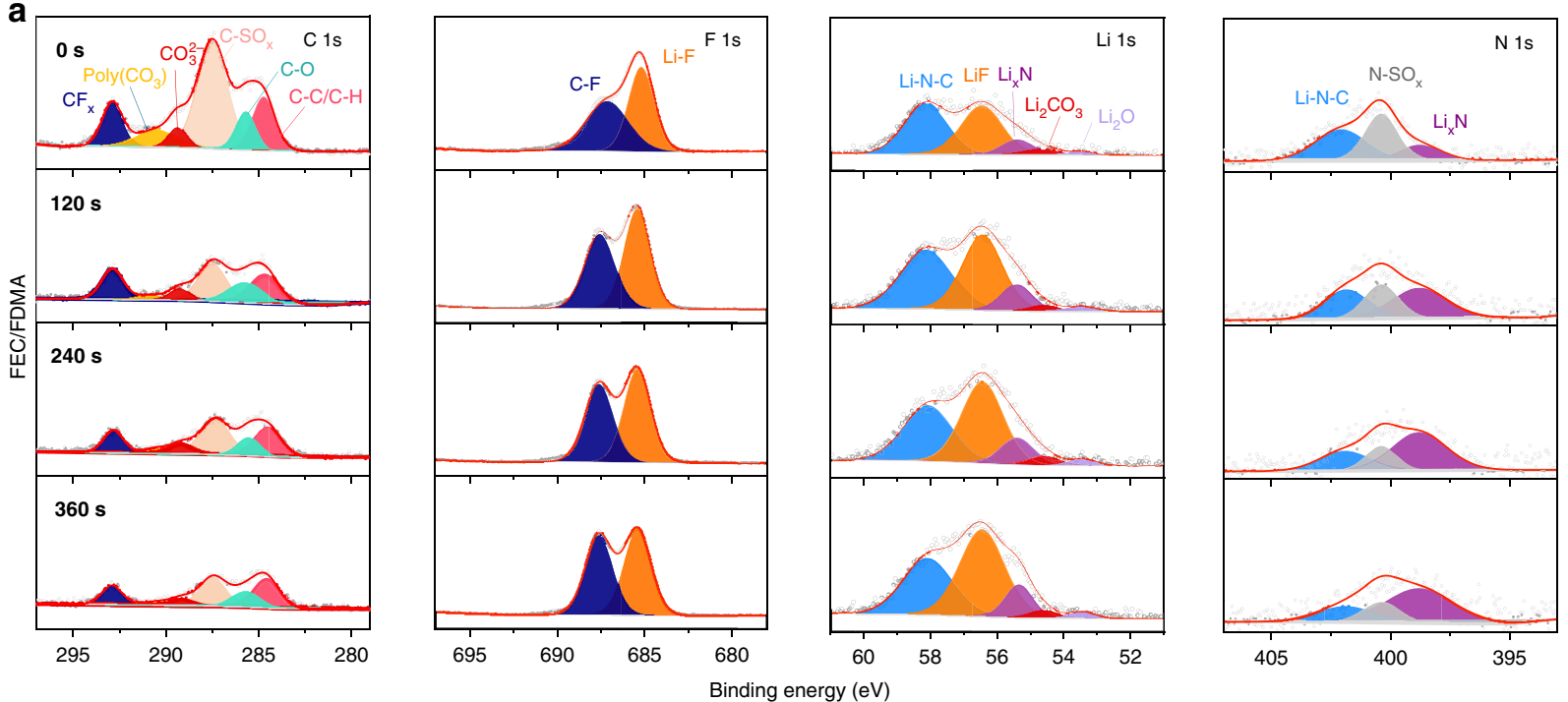

b
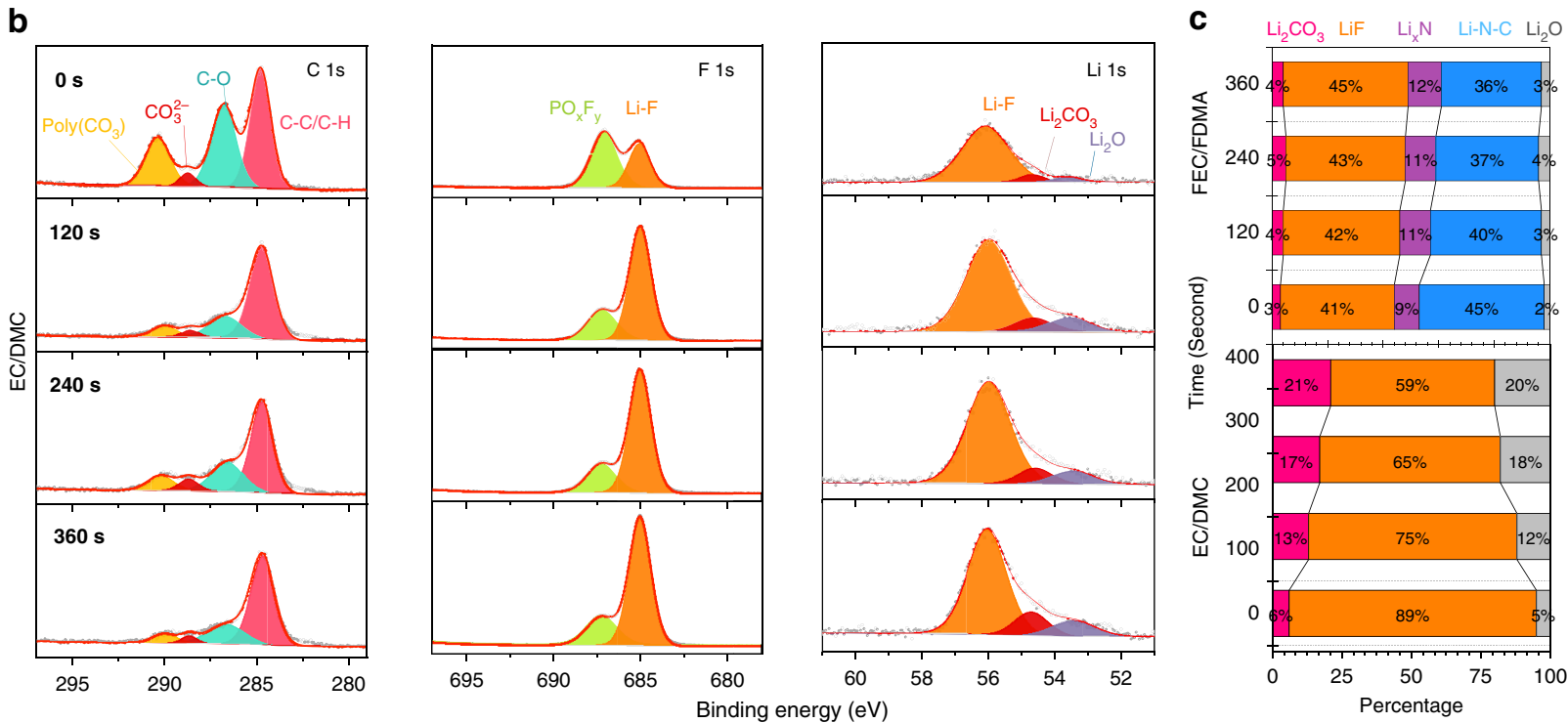

Fig. 4 Components on the surface of anodes after cycling. a, b X-ray photoelectron spectroscopy (XPS) depth profiles of C 1s, $\mathrm{F} 1 \mathrm{~s}$, Li 1s and $\mathrm{N}$ 1s spectra of Li metal anodes after 50 cycles for both electrolytes. c The relative composition of Li-containing species.

anodes for both the amide-based electrolyte (Fig. 4a) and the conventional EC-based electrolyte (Fig. 4b), where the survey spectra is shown in Supplementary Fig. 13. In the C 1s spectra, both electrolytes present the commonly observed species, including $\mathrm{C}-\mathrm{C} / \mathrm{C}-\mathrm{H}(\sim 284.8 \mathrm{eV}), \mathrm{C}-\mathrm{O}(\sim 285.7 \mathrm{eV}), \mathrm{CO}_{3}{ }^{2-}$ $(\sim 289.3 \mathrm{eV})$ as well as poly $\left(\mathrm{CO}_{3}\right)(\sim 290.3 \mathrm{eV})^{40,41}$. In contrast, for the amide electrolyte, two additional peaks appear that can be attributed to C-SO $(\sim 287.6 \mathrm{eV})^{18}$ and $\mathrm{CF}_{\mathrm{x}}(\sim 292.9 \mathrm{eV})^{42,43}$, most likely resulting from LiTFSI or FDMA. The existence of $\mathrm{CF}_{\mathrm{x}}$ $(\sim 687.6 \mathrm{eV})$ is further supported by the F 1s spectra, and the other peak at $\sim 685 \mathrm{eV}$ corresponds to LiF, which suggests the preferred reaction of FEC with Li metal ${ }^{44,45}$. For the EC-based electrolyte, the two major peaks at $\sim 687$ and $685 \mathrm{eV}$ can be attributed to fluorophosphates $\left(\mathrm{PO}_{\mathrm{x}} \mathrm{F}_{\mathrm{y}}\right)$ and LiF, most likely generated via the reactions of $\mathrm{PF}_{5}$ and/or $\mathrm{PF}_{6}$ groups with $\mathrm{Li}$ metal, which testify the participation of $\mathrm{LiPF}_{6}$ in the SEI formation. For the Li 1s spectrum of the EC-based electrolyte, the peak in the range of $\sim 53-56 \mathrm{eV}$ can be deconvoluted into three components centered at $\sim 55.7 \mathrm{eV}, \sim 54.3 \mathrm{eV}$ and $\sim 53.2 \mathrm{eV}$, which can be assigned to LiF, $\mathrm{Li}_{2} \mathrm{CO}_{3}$ and $\mathrm{Li}_{2} \mathrm{O}$, respectively ${ }^{46}$. For the amide system, two more peaks appear in the $\mathrm{Li} 1 \mathrm{~s}$ spectrum, centered at $\sim 58.1 \mathrm{eV}$ and $\sim 55.7 \mathrm{eV}$, which can be assigned to two $\mathrm{N}$-containing species, $\mathrm{Li}-\mathrm{N}-\mathrm{C}$ and $\mathrm{Li}_{\mathrm{x}} \mathrm{N}$, originating from the decomposition of FDMA and LiTFSI. From the results, the relative amount of Licontaining species at different depths is determined as shown in Fig. 4c. For both systems LiF accounts for a large portion of the SEI, where for the amide system, $\mathrm{Li}-\mathrm{N}$ species (including $\mathrm{Li}-\mathrm{N}-\mathrm{C}$ and $\mathrm{Li}_{\mathrm{x}} \mathrm{N}$ ) dominate the SEI chemistry. These $\mathrm{Li}-\mathrm{N}$ species can be identified more clearly in the $\mathrm{N} 1 \mathrm{~s}$ spectrum, where the three deconvoluted contributions $(\sim 402.1, \sim 400.4$ and $\sim 398.7 \mathrm{eV})$ can be assigned to $\mathrm{Li}-\mathrm{N}-\mathrm{C}, \mathrm{N}-\mathrm{SO}_{\mathrm{x}}$ and $\mathrm{Li}_{\mathrm{x}} \mathrm{N}$, respectively $42,47,48$. After sputtering, the $\mathrm{Li}_{\mathrm{x}} \mathrm{N}$ signal becomes more apparent, along with a decrease of the $\mathrm{Li}-\mathrm{N}-\mathrm{C}$ signal, which can be explained by the different reduction products of FDMA, depending on the amount of reacting $\mathrm{Li}^{+}$and $\mathrm{e}^{-}$as studied by the DFT calculations. In the inner part of the SEI, where electrons are able to reduce FDMA, it is more favorable to form $\mathrm{Li}_{\mathrm{x}} \mathrm{N}$, while the poor electronic conductivity of the SEI makes that only the first decomposition products form at the outer part of the SEI.

Evolution of Li-metal density during plating and stripping. Operando neutron depth profiling (NDP) allows non-invasive 


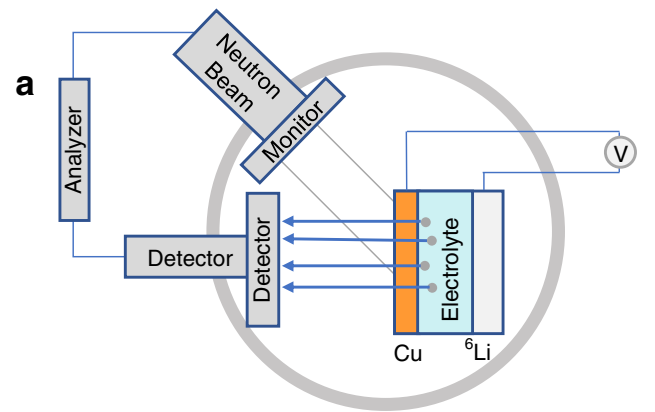

b

${ }^{6} \mathrm{Li}^{+}+\rightarrow{ }^{4} \mathrm{He}^{2+}(2044 \mathrm{keV})+{ }^{3} \mathrm{H}^{+}(2727 \mathrm{keV})$
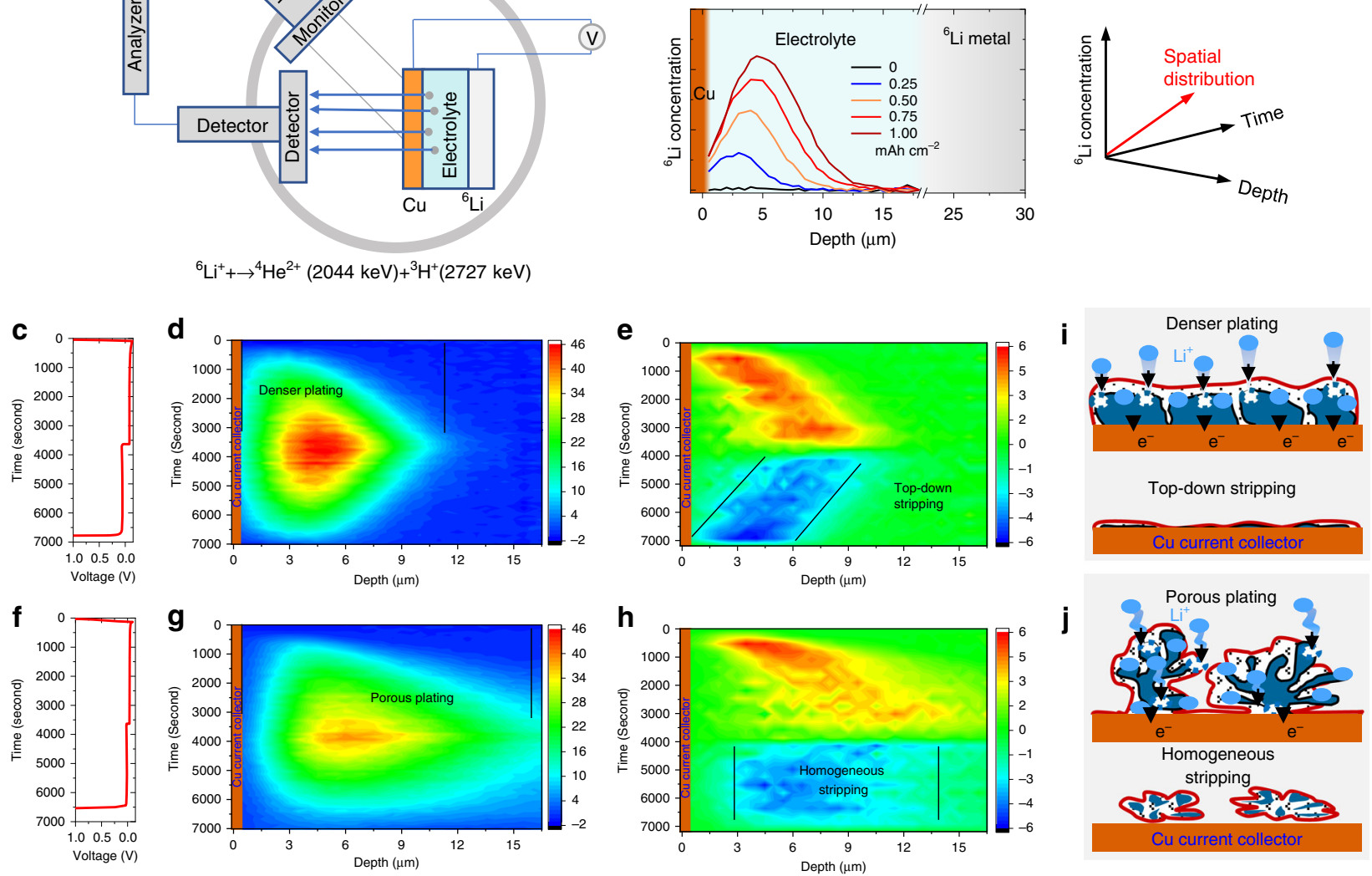

Fig. $5 \mathbf{~ L i}^{+}$plating/stripping by operando neutron depth profile. a The schematic operando neutron depth profile (NDP) setup. $\mathbf{b}$ Depth profiles during $\mathrm{Li}$ metal plating/stripping on a Cu working electrode cycled at a current density of $1 \mathrm{~mA} \mathrm{~cm}^{-2}$ to a capacity of $1 \mathrm{mAh} \mathrm{cm}-2$ of $\mathbf{c} 1 \mathrm{M} \mathrm{LiTFSI-FEC/FDMA} \mathrm{and} \mathbf{f} 1$ $M \mathrm{LiPF}_{6}-\mathrm{EC} / \mathrm{DMC}$ electrolytes. Evolution of $\mathrm{Li}^{+}$plating/stripping density vs. time from operando NDP during the first cycle at $1 \mathrm{mAh} \mathrm{cm}^{-2}$ in $\mathrm{Li} \| \mathrm{Cu}$ pouch cells for $\mathbf{d} 1 \mathrm{M}$ LiTFSI-FEC/FDMA and $\mathbf{g} 1 \mathrm{M} \mathrm{LiPF}_{6}-\mathrm{EC} / \mathrm{DMC}$ electrolytes. The depth is calculated starting from the inner surface of the Cu current collector. Evolution of $\mathrm{Li}^{+}$plating/stripping activity for $\mathbf{e} 1 \mathrm{M}$ LiTFSI-FEC/FDMA and $\mathbf{h} 1 \mathrm{M} \mathrm{LiPF}{ }_{6}-\mathrm{EC} / \mathrm{DMC}$ electrolytes, which is obtained from the change in $\mathrm{Li}^{+}$ density upon each time step of $\mathbf{d}$ and $\mathbf{g}$, respectively. The color scale in NDP measurements indicates the local Li concentration in mol/liter. $\mathbf{i}$ and $\mathbf{j}$ Schematic representation of the plating/stripping mechanism in the two electrolytes.

monitoring of the spatial and temporal distribution of Li during electrochemical plating/stripping, providing direct visualization of the $\mathrm{Li}^{+}$transport and irreversible processes ${ }^{49,50}$. The schematic setup of the operando NDP measurement and the corresponding principle are shown in Fig. 5a. Through the neutron capture reaction of the ${ }^{6} \mathrm{Li}^{+}$isotope (natural abundance $7.5 \%$ ), two charged particles with a well-defined energy are produced, ${ }^{4} \mathrm{He}^{2+}$ $\left(\mathrm{E}_{\mathrm{k}}=2044 \mathrm{keV}\right)$ and ${ }^{3} \mathrm{H}^{+}\left(\mathrm{E}_{\mathrm{k}}=2727 \mathrm{keV}\right)$. Due to the lower charge of the ${ }^{3} \mathrm{H}^{+}$particles, these are able to exit the pouch cells, whereas the stopping power towards ${ }^{4} \mathrm{He}^{2+}$ is too large to penetrate the current collector ${ }^{49}$. Based on calculating the energy loss of the ${ }^{3} \mathrm{H}^{+}$particles, measured in the detector positioned perpendicular to the electrode, the ${ }^{6} \mathrm{Li}^{+}$density depth profile can be monitored during battery operation as shown in Fig. 5b. With a sub-micron depth resolution, and time resolution in the order of minutes, Operando NDP provides the unique opportunity to monitor Li plating/stripping quantitatively, under realistic electrochemical conditions.

Cycled at a current density of $1 \mathrm{~mA} \mathrm{~cm}^{-2}$ with a capacity of 1 $\mathrm{mAh} \mathrm{cm}{ }^{-2}$, the evolution of $\mathrm{Li}^{+}$plating/stripping density vs. time are obtained from operando NDP during the first cycle in $\mathrm{Li} \| \mathrm{Cu}$ pouch cells for the $1 \mathrm{M}$ LiTFSI-FEC/FDMA (Fig. 5c, d) and $1 \mathrm{M}$ $\mathrm{LiPF}_{6}$-EC/DMC (Fig. 5f, g) electrolytes, respectively. As demonstrated by Fig. 5 d, a denser and thinner Li deposition is observed for the amide-based electrolyte. In comparison, a much less compact and thicker Li deposit is observed for the EC-based electrolyte, extending to $18 \mu \mathrm{m}$ into the electrolyte. These results are in good agreement with the ex situ SEM and in situ optical microscopy measurements in Fig. 3. It's worth mentioning that the NDP measurements provide a more precise picture of the $\mathrm{Li}$ deposition as compared to the in situ optical microscopy, because for the latter there is a large space between the Li-metal and separator to get a clear observation of the Li-deposits, which is different to the practical cell. In the EC-based electrolyte, the Li density profile in Fig. $5 \mathrm{~g}$ demonstrates a clear asymmetry comparing plating and stripping, consistent with the optical analysis. This phenomenon is more clearly visualized in the time derivative of the Li density, shown in Fig. 5h, representing the depth-resolved plating/stripping activity. The Li-metal stripping in the EC electrolyte is homogeneously distributed over the thickness of the deposit, whereas the stripping activity in the amide electrolyte moves back symmetrically, as compared to the plating, to the current collector. Homogeneous stripping will result in a porous Li-metal morphology, which promotes the formation of a high surface area and of Li-metal domains that are disconnected from the $\mathrm{Cu}$ current collector, thus resulting in the formation of "dead" Li. In contrast, stripping from the top of the deposit, as observed for the amide electrolyte in Fig. 5e and 
Supplementary Fig. 14, suggests a much more reversible stripping mechanism. Also, at higher and lower current densities, 0.5 and $5 \mathrm{~mA} \mathrm{~cm}^{-2}$, the evolution of the Li density still keeps reversible during plating and stripping using the amide electrolyte as shown in Supplementary Fig. 15 and Supplementary Fig. 16, respectively. The ability of NDP to quantitatively monitor the amount of $\mathrm{Li}$ metal on the current collector allows us to determine the $\mathrm{Li}$ efficiency, defined as the ratio between the stripped and the plated Li mass. This provides complementary information to the electron efficiency (Coulombic efficiency) where the difference quantifies the amount of irreversible reactions that do not involve Li-ion transfer, such as direct electrolyte reduction and chemical dissolution of Li from the SEI. Comparison between the Li-mass evolution in different electrolytes is shown in Supplementary Fig. 17, the amide electrolyte shows a better Li-efficiency and a higher Li mass after plating, indicating a lower amount of parasitic reduction reactions.

The origin of the top-down stripping and/or more reversible plating/stripping can be rationalized by the schematic representation in Fig. 5i, j. According to the XPS results, the SEI formed in the as-prepared electrolyte contains more ionic conductive components, which can be responsible for the denser Li metal deposits observed with operando NDP, as well as with SEM (Fig. 3b) and in situ optical microscopy measurements (Fig. 3d). Compared to the more porous Li metal/SEI morphology in the conventional electrolyte, compact Li metal deposition will allow more facile electron transport from the surface of the deposits to the $\mathrm{Cu}$ current collector, which will facilitate stripping from the top. In contrast, a more porous deposition will compromise electron transport and facilitate ion transport, resulting in relatively homogenous stripping. The consequential formation of isolated regions of $\mathrm{Li}$ metal, alongside a larger amount of decomposition reactions due to the porous morphology, will lower the Coulombic efficiency and hence shortening the cycle life.

Electrochemical performance of full cells. Ni-rich compounds are considered to be promising cathode materials for LIBs due to their large capacity, which in combination with a Li-metal anode results in a very high energy density ${ }^{19,51-53}$. In this context, NCM811 with a high active mass loading of $3.5 \mathrm{mAh} \mathrm{cm}^{-2}$ is used to test the performance of the prepared amide electrolyte. The high cathode mass loading aggravates the side reactions and requires a high efficiency of the Li-metal utilization ${ }^{54}$. Both Lill NCM811 cells, employing the different electrolytes, deliver similar initial charge and discharge voltage profiles, resulting in a specific capacity of $195 \mathrm{mAh} \mathrm{g}^{-1}$, shown in Fig. 6a, b. Upon subsequent cycling, the full cells with the amide electrolyte present much better cycling stability, retaining $>88 \%$ of its initial capacity after 500 cycles as shown in Fig. $6 c$, and a high average Coulombic efficiency as shown in Supplementary Fig. 18. In comparison, the battery with the EC-based electrolyte rapidly decays to $\sim 30 \%$ after 75 cycles as shown in Fig. 6a, c. Evaluation of the C-rate charging-discharging performance of the full cells, see Supplementary Fig. 19, demonstrates better rate capabilities for the amide-based electrolyte. This is in line with the smaller impedance observed, shown in Supplementary Fig. 20, which demonstrates the good compatibility of the amide electrolyte in full Li-metal cells. Furthermore, the full cycling history of a Lill NCM811 full cell with a restricted Li capacity is evaluated in Fig. $6 c$, where the Li-metal capacity on the $\mathrm{Cu}$ current exceeds the cathode capacity $\left(\sim 3.5 \mathrm{mAh} \mathrm{cm}^{-2}\right)$ by a factor of 1.5 . Under these demanding conditions stable cycling performance is achieved as $>92 \%$ of the capacity is retained for 100 cycles. In addition, when FDMA is added to the conventional electrolyte system, as shown in Supplementary Fig. 21, the Li||NCM811 full cell using $1 \mathrm{M}$ $\mathrm{LiPF}_{6}-\mathrm{EC} / \mathrm{DMC} / \mathrm{FDMA}$ (volume ratio 1:1:1) exhibits improved cycling stability compared with using $1 \mathrm{M} \mathrm{LiPF}_{6}$-EC/DMC.

Interface between cathode and electrolyte. The interface stability between cathode and electrolyte is further investigated by SEM and TEM. After 50 cycles in full cells, the morphology of the cathode materials is well preserved in the amide electrolyte, while obvious cracks and pulverization of the cathode are observed for the secondary particles in the EC-based electrolyte, see Supplementary Figs. 22 and 23. This indicates that the as-prepared amide electrolyte can suppress the structural degradation of NCM cathode materials. More evidence is provided by the transmission electron microscope (TEM) characterization. When cycled in the EC-based electrolyte, severe surface damage on the cycled cathodes is observed in Supplementary Fig. 24a, indicated by the yellow dashed lines. The corresponding fast Fourier transforms (FFT) patterns of the near-surface regions, up to $12 \mathrm{~nm}$ in depth, demonstrate the phase transition from the original layered structure to the rock-salt phase at the surface. In contrast, the surface layer on the particle cycled in the amide electrolyte is much thinner, $\sim 4 \mathrm{~nm}$, and more uniform. Moreover, it is mainly composed of amorphous cathode electrolyte interface (CEI) components as shown in Supplementary Fig. 24b. This indicates that this amide electrolyte effectively protects the cathode surface. Energy dispersive spectroscopy mapping clearly shows the presence of $\mathrm{N}$ - and F-containing components in the CEI layer, Supplementary Fig. 24c, explaining the decreased resistance and the improved electrochemical stability.

Furthermore, the chemical composition of CEI layers is investigated by XPS, results of which are shown in Supplementary Figs. 25-30. In the EC-based electrolyte, four peaks in the $\mathrm{O} 1 \mathrm{~s}$ spectrum, located at about 530.5, 532.1, 533.4, and $534.3 \mathrm{eV}$, can be indexed as $\mathrm{M}-\mathrm{O}$ (metal oxide from the cathode bulk), $\mathrm{C}=\mathrm{O}$, $\mathrm{C}-\mathrm{O}$, and $\mathrm{Poly}\left(\mathrm{CO}_{3}\right)$, respectively ${ }^{55}$. The appearance of the $\mathrm{M}-\mathrm{O}$ species indicates that the CEI layer is cracked and non-uniform, exposing the cathode surface. In the $\mathrm{O} 1 \mathrm{~s}$ and $\mathrm{F} 1 \mathrm{~s}$ spectra of the amide electrolyte, a new peak indicates the presence of $-\mathrm{CF}_{3}$, which may originate from either the LiTFSI salt or FDMA. In addition, the CEI formed in the amide electrolyte is richer in $\mathrm{LiF}$, as demonstrated by Supplementary Fig. 26. LiF has a large oxidative stability and excellent mechanical stability, which can be held responsible for the high-voltage stability of the CEI layer ${ }^{17,19}$. The $\mathrm{N}$-containing species are also observed in the CEI layer of the amide electrolyte, which provides the required $\mathrm{Li}$ transport through the CEI layer. These results demonstrate that the amide electrolyte, through the synergy between both the FEC and FDMA, also provides a homogeneous and stable CEI protective layer, leading to the improved electrochemical performance of the full cells.

\section{Discussion}

In this work, a new electrolyte is prepared that enables highly reversible and stable cycling of lithium metal batteries. The asprepared electrolyte, combining FDMA with FEC as a cosolvent, shows significantly enhanced electrochemical performance of $\mathrm{Li}$ metal anodes in combination with high-loading Ni-rich batteries as compared to conventional carbonate-based electrolytes. The rationale behind this is the relatively low LUMO level of FDMA, which initiates decomposition into ion-conductive $\mathrm{N}$-containing components. In combination with the highly stable Fcomponents in both SEI and CEI layers, Li dendrites and porous Li-metal morphologies are reduced and both anode and cathode degradation are effectively prevented. Monitoring the Limetal deposition with in situ optical microscopy and operando 
a

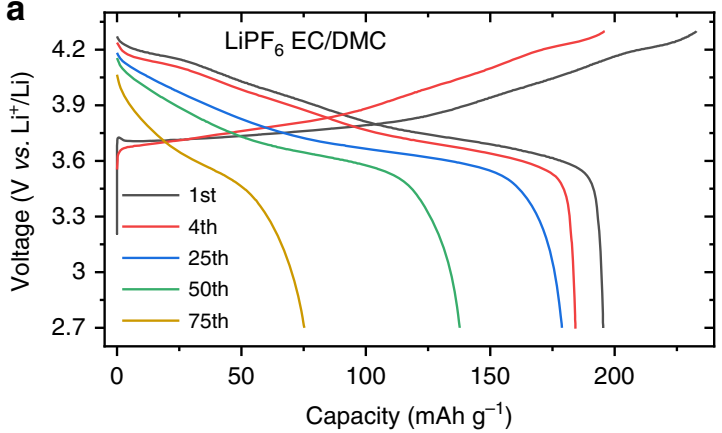

b

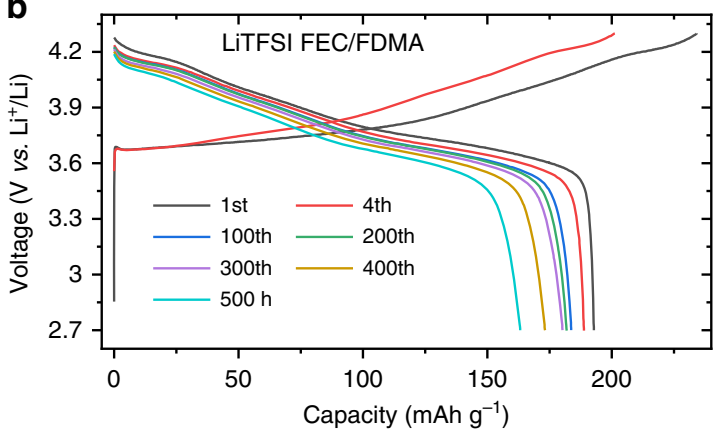

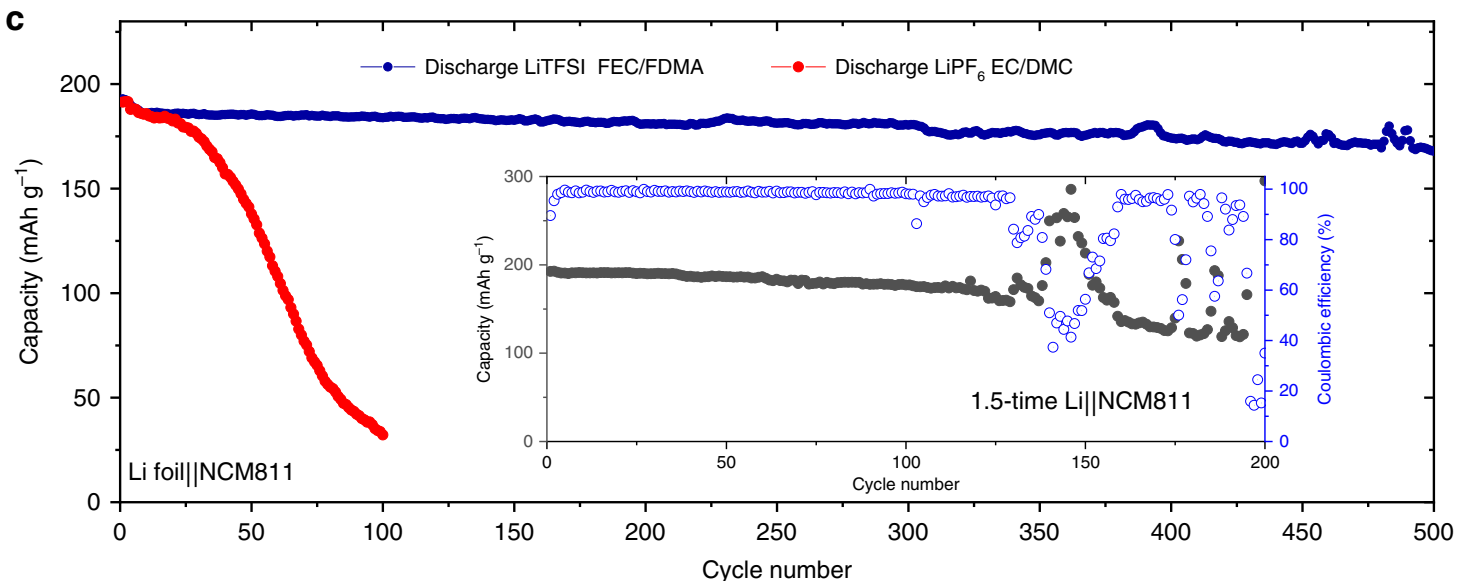

Fig. 6 Electrochemical behavior of full cells using NCM811 as cathode. $\mathbf{a}$, b Galvanostatic charge-discharge curves of Li\|NCM811 cells in $1 \mathrm{M}$ LiPF ${ }_{6}$-EC/ DMC and $1 \mathrm{M}$ LiTFSI-FEC/FDMA. c Cycling stability of Li||NCM811 cells at rate of $0.25 \mathrm{C}$ with first three cycles at $0.1 \mathrm{C}$. The inset shows the cycling history of the Li||NCM811 full cells with negative to positive electrode capacity ratio of 1.5 .

NDP shows that the amide-based electrolyte is responsible for denser $\mathrm{Li}$ deposition, which induces $\mathrm{Li}^{+}$stripping from the top of the deposit towards the current collector. As opposed to homogeneous stripping observed in carbonate electrolytes, the topdown stripping lowers the chance to form inactive regions of $\mathrm{Li}$ metal and contributes to less porous morphologies, hence suppressing irreversible reactions, which is responsible for the large Coulombic efficiency. The understanding of the relationship between the interface chemistry and the $\mathrm{Li}^{+}$plating/stripping mechanism in this promising electrolyte, opens up new opportunities to improve the reversibility of lithium metal batteries.

\section{Methods}

Materials. Battery grade ethylene carbonate (EC, Sigma-Aldrich) and dimethyl carbonate (DMC, Novolyte) (1:1 volume ratio), lithium hexafluorophosphate $\left(\mathrm{LiPF}_{6}\right.$, Sigma-Aldrich), lithium bis(trifluoromethanesulfonyl)imide (LiTFSI, Sigma-Aldrich) and fluoroethylene carbonate (FEC, Sigma-Aldrich) were used and stored in a Ar glovebox with measured levels of oxygen and water contents below $1.0 \mathrm{ppm}$. 2,2,2-Trifluoro- $\mathrm{N}, \mathrm{N}$-dimethylacetamide (FDMA, $>98.0 \%(\mathrm{GC})$ ), was purchased from Tokyo Chemical Industry Co., Ltd with further dehydration. Single glass fiber (Whatman, GF/A) separator is used for all cells. The $\mathrm{LiNi}_{0.8^{-}}$ $\mathrm{Co}_{0.1} \mathrm{Mn}_{0.1} \mathrm{O}_{2}$ (NCM811) electrode contains $94.5 \mathrm{wt} \%$ active material, $3 \mathrm{wt} . \%$ conductive carbon, and $2.5 \mathrm{wt} . \%$ polyvinylidene fluoride binder in $\mathrm{N}$-methyl-2pyrrolidone coated on an aluminum (Al) current collector foil with an active material mass loading of $18 \mathrm{~m} \mathrm{~cm}^{-2}$. The electrodes were punched into disks with a diameter of $12 \mathrm{~mm}$ and dried under vacuum for $12 \mathrm{~h}$ at $80^{\circ} \mathrm{C}$ before use.

Electrochemical measurements. $\mathrm{Li}\|\mathrm{Cu}, \mathrm{Li}\| \mathrm{Li}$ and $\mathrm{Li}|| \mathrm{NCM} 811$ cells were assembled in standard 2032 coin-type cells using GF/A separator and about $70 \sim 120 \mu \mathrm{L}$ electrolyte in the Ar-filled glove box with oxygen and water contents below $1.0 \mathrm{ppm}$. The cells were tested on a Maccor 4400 cycling system. The copper foil for $\mathrm{Li} \| \mathrm{Cu}$ cells were pouched into disks with diameter of $16 \mathrm{~mm}$ as working electrodes, while Li metal was used as the reference and counter electrode. During each cycle, a designed amount of $\mathrm{Li}$ was deposited on the $\mathrm{Cu}$ foil at a specific current density and then stripped until the potential reached $1.0 \mathrm{~V} \mathrm{vs.} \mathrm{Li}^{+} / \mathrm{Li}$.
Symmetric $\mathrm{Li}|| \mathrm{Li}$ cells were also assembled to study the cycling stability under different current densities in different electrolytes. Li||NCM811 full cells using Li foil as the anode were cycled in galvanostatic mode with a voltage range of $2.7-4.3 \mathrm{~V}$. The electrolyte weight to cathode capacity ratio in $1 \mathrm{M}$ LiTFSI-FEC/ FDMA is around $30 \mathrm{~g} \mathrm{Ah}^{-1}$, and that in $1 \mathrm{M} \mathrm{LiPF}_{6}-\mathrm{EC} / \mathrm{DMC}$ is around $25 \mathrm{~g} \mathrm{Ah}^{-1}$. Linear sweep voltammetry (LSV) was conducted with stainless steel served as working electrode and Li metal foil as both counter and reference electrodes. The LSV measurements were carried out on an Autolab (PGSTAT302N) with a scan

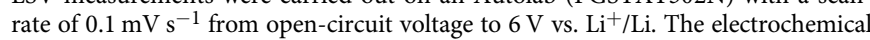
impedance spectra (EIS) of the symmetric cells and full cells were collected on an Autolab (PGSTAT302N) in the frequency range of $0.1 \mathrm{~Hz}-1 \mathrm{MHz}$ with a potential amplitude of $10 \mathrm{mV}$. The Li metal anode for the Li\|NCM811 full cell with a restricted Li capacity is prepared by electrochemical plating. A Li $\| \mathrm{Cu}$ cell using $1 \mathrm{M}$ LiTFSI-FEC/FDMA was discharged at $1 \mathrm{~mA} \mathrm{~cm}^{-2}$ to a capacity of 1.5 times that of the NCM811 electrode, subsequently, the cell was disassembled to obtain the thin Li metal anode.

Characterizations. The morphology of electrodes cycled with different electrolyte were characterized by SEM (SEM, Hitachi SU-4800). Before the sample was mounted on the sample holder, the deposited $\mathrm{Li}$ metal on the $\mathrm{Cu}$ foil and the NCM811 electrode after 50 cycles were disassembled and washed 3 times with anhydrous DMC to remove the residual electrolyte and dried in the glovebox to remove the solvent residual. To characterize the detailed surface morphology of the cathode powder after cycling, transmission electron microscopy (TEM, FEI Tecnai G2 spirit) was used.

The XPS testing was carried out to analyze the composition of both anode and NCM811 cathode after cycling, the cells were disassembled in an Ar-filled glove box. The electrodes were rinsed with DMC solvent 3 times to remove residual electrolyte, followed by dried under vacuum condition for $12 \mathrm{~h}$ at room temperature to remove the solvent residual. The element composition on the surface of the electrodes was analyzed by X-ray photoelectron spectroscopy (XPS, PHI 5000 VersaProbe II) using monochromatic Al K(alpha) X-ray source calibrated with respect to carbon $(284.8 \mathrm{eV})$. Peak fitting was performed using MultiPak software.

Symmetric cells were assembled in a special designed optical cell for in situ observation. The assembly process were performed in an Argon-filled glovebox with water and oxygen content below $1.0 \mathrm{ppm}$. Li foils and glass fiber separator were placed into the optical cell vertically. After the electrolyte was injected, the 
whole cell was transferred to the optical microscope (Olympus BXFM) located in the glovebox, and was cycled using a CT2001A tester (LAND Electronic Co. Ltd., Wuhan). In situ observations were carried out in the glovebox at ambient temperature in dark field shooting by a fitted charge-coupled device (CCD) camera on the microscope.

Operando neutron depth profiling (NDP) was performed on the thermal neutron beamline at the Reactor Institute Delft, the Netherlands. The specially designed air-tight $\mathrm{Li} \| \mathrm{Cu}$ pouch cell with a window for the NDP experiments was assembled using ${ }^{6} \mathrm{Li}$ metal $\left(95 \%\right.$ wt. $\%{ }^{6} \mathrm{Li}$ and $5 \%$ wt. $\left.\%{ }^{7} \mathrm{Li}\right)$, Glass fiber disks (GF/ A, Whatman) next to a $25 \mu \mathrm{m}$ PE (Celgard), Cu foil ( $10 \mu \mathrm{m}$, as working electrode and the window), and $150 \mu \mathrm{l}$ electrolyte. The pouch cell was fixed inside the stainless-steel chamber filled by a 1 bar He atmosphere, and the whole box was fixed in to an $\mathrm{Al}$ vacuum chamber, where the experiments were performed. The cells are positioned at an angle of $30^{\circ}$ towards the incident neutron beam and parallel to the Canberra PIPS detector placed perpendicular to the battery electrodes at $4.5 \mathrm{~cm}$ from the pouch cells in order to measure the energy of the emitted ${ }^{3} \mathrm{H}$ particles. Galvanostatic cycling was performed using a Maccor 4000 cycling system by plating $\mathrm{Li}$ onto the $\mathrm{Cu}$ working electrode at $1 \mathrm{~mA} \mathrm{~cm}-2$ to a total capacity of $1 \mathrm{mAh} \mathrm{cm}^{-2}$ followed by stripping to a cut-off voltage of $1.0 \mathrm{~V}$ vs. $\mathrm{Li}^{+} / \mathrm{Li}$. SRIM was used to calibrate the stopping power of the materials for converting the triton $\left({ }^{3} \mathrm{H}\right)$ energy loss and intensity to the Li depth and $\mathrm{Li}$ density $^{56}$. For the calculation of the stopping power and the depth calibration, we refer to previous work ${ }^{49,57}$.

Calculations. Quantum chemical calculations were conducted using density functional theory (DFT) method with Becke's three parameters (B3) exchange functional in Lee-Yang-Parr (LYP) nonlocal correlation functional (B3LYP) ${ }^{58,59}$ All the geometry optimizations were proceeded with B3LYP/6-31+G(d,p) level. The energy calculations were performed at B3LYP/6-311+ $+\mathrm{G}$ (3df,3dp) level for more accurate calculation. All DFT calculations were performed by using the Gaussian 09 program package ${ }^{60}$

\section{Data availability}

The data that support the findings within this paper are available from the corresponding author on request.

Received: 8 February 2020; Accepted: 29 July 2020;

Published online: 21 August 2020

\section{References}

1. Xia, C., Kwok, C. Y. \& Nazar, L. F. A high-energy-density lithium-oxygen battery based on a reversible four-electron conversion to lithium oxide. Science 361, 777 (2018).

2. Liang, X. et al. A facile surface chemistry route to a stabilized lithium metal anode. Nat. Energy 2, 17119 (2017).

3. Goodenough, J. B. \& Kim, Y. Challenges for rechargeable Li batteries. Chem. Mater. 22, 587-603 (2010).

4. Kim, H. et al. Metallic anodes for next generation secondary batteries. Chem. Soc. Rev. 42, 9011-9034 (2013).

5. Xu, W. et al. Lithium metal anodes for rechargeable batteries. Energy Environ. Sci. 7, 513-537 (2014).

6. Lin, D., Liu, Y. \& Cui, Y. Reviving the lithium metal anode for high-energy batteries. Nat. Nanotech 12, 194 (2017).

7. Cheng, X.-B., Zhang, R., Zhao, C.-Z. \& Zhang, Q. Toward safe lithium metal anode in rechargeable batteries: a review. Chem. Rev. 117, 10403-10473 (2017).

8. Li, Y. et al. Atomic structure of sensitive battery materials and interfaces revealed by cryo-electron microscopy. Science 358, 506 (2017).

9. Chazalviel, J. N. Electrochemical aspects of the generation of ramified metallic electrodeposits. Phy. Rev. A 42, 7355-7367 (1990).

10. Aurbach, D., Zinigrad, E., Cohen, Y. \& Teller, H. A short review of failure mechanisms of lithium metal and lithiated graphite anodes in liquid electrolyte solutions. Solid State Ion. 148, 405-416 (2002).

11. Verma, P., Maire, P. \& Novák, P. A review of the features and analyses of the solid electrolyte interphase in Li-ion batteries. Electrochim. Acta 55, 6332-6341 (2010).

12. Yamada, Y., Wang, J., Ko, S., Watanabe, E. \& Yamada, A. Advances and issues in developing salt-concentrated battery electrolytes. Nat. Energy 4, 269-280 (2019).

13. Parimalam, B. S. \& Lucht, B. L. Reduction reactions of electrolyte salts for lithium ion batteries: LiPF6, LiBF4, LiDFOB, LiBOB, and LiTFSI. J. Electrochem. Soc. 165, A251-A255 (2018).

14. Delp, S. A. et al. Importance of reduction and oxidation stability of high voltage electrolytes and additives. Electrochim. Acta 209, 498-510 (2016).
15. Aurbach, D. \& Granot, E. The study of electrolyte solutions based on solvents from the "glyme" family (linear polyethers) for secondary Li battery systems. Electrochim. Acta 42, 697-718 (1997).

16. Zhang, X., Kostecki, R., Richardson, T. J., Pugh, J. K. \& Ross, P. N. Electrochemical and infrared studies of the reduction of organic carbonates. J. Electrochem. Soc. 148, A1341-A1345 (2001).

17. Suo, L. et al. Fluorine-donating electrolytes enable highly reversible 5-V-class Li metal batteries. Proc. Natl Acad. Sci. U.S.A. 115, 1156 (2018).

18. Jiao, S. et al. Stable cycling of high-voltage lithium metal batteries in ether electrolytes. Nat. Energy 3, 739-746 (2018).

19. Fan, X. et al. Non-flammable electrolyte enables Li-metal batteries with aggressive cathode chemistries. Nat. Nanotech 13, 715-722 (2018).

20. Zheng, J. et al. Electrolyte additive enabled fast charging and stable cycling lithium metal batteries. Nat. Energy 2, 17012 (2017).

21. Shi, Q., Zhong, Y., Wu, M., Wang, H. \& Wang, H. High-capacity rechargeable batteries based on deeply cyclable lithium metal anodes. Proc. Natl Acad. Sci. U.S.A. 115, 5676 (2018).

22. Chen, S. et al. High-voltage lithium-metal batteries enabled by localized highconcentration electrolytes. Adv. Mater. 30, el706102 (2018).

23. Chen, S. et al. High-efficiency lithium metal batteries with fire-retardant electrolytes. Joule 2, 1548-1558 (2018).

24. Wang, C., Meng, Y. S. \& Xu, K. Perspective-fluorinating Interphases. J. Electrochem Soc. 166, A5184-A5186 (2019).

25. Andersson, A. M. \& Edström, K. Chemical composition and morphology of the elevated temperature SEI on graphite. J. Electrochem. Soc. 148, A1100-A1109 (2001)

26. Aurbach, D. Electrode-solution interactions in Li-ion batteries: a short summary and new insights. J. Power Sources 119-121, 497-503 (2003)

27. Aurbach, D., Markovsky, B., Weissman, I., Levi, E. \& Ein-Eli, Y. On the correlation between surface chemistry and performance of graphite negative electrodes for Li ion batteries. Electrochim. Acta 45, 67-86 (1999).

28. Park, M. S. et al. A highly reversible lithium metal anode. Sci. Rep. 4, 3815 (2014).

29. Chen, Y., Freunberger, S. A., Peng, Z., Bardé, F. \& Bruce, P. G. Li-O2 battery with a dimethylformamide electrolyte. J. Am. Chem. Soc. 134, 7952-7957 (2012).

30. Halls, M. D. \& Tasaki, K. High-throughput quantum chemistry and virtual screening for lithium ion battery electrolyte additives. J. Power Sources 195, 1472-1478 (2010).

31. Jozwiuk, A. et al. The critical role of lithium nitrate in the gas evolution of lithium-sulfur batteries. Energy Environ. Sci. 9, 2603-2608 (2016).

32. Rosenman, A. et al. The effect of interactions and reduction products of LiNO3, the anti-shuttle agent, in Li-S battery systems. J. Electrochem. Soc. 162, A470-A473 (2015).

33. Aurbach, D. et al. On the Surface chemical aspects of very high energy density, rechargeable Li-Sulfur batteries. J. Electrochem. Soc. 156, A694-A702 (2009)

34. Liu, M. et al. Efficient Li-metal plating/stripping in carbonate electrolytes using a LiNO3-gel polymer electrolyte, monitored by operando neutron depth profiling. Chem. Mater. 31, 4564-4574 (2019).

35. Liu, Y. et al. Solubility-mediated sustained release enabling nitrate additive in carbonate electrolytes for stable lithium metal anode. Nat. Commun. 9, 3656 (2018).

36. Kim, K. et al. Understanding the thermal instability of fluoroethylene carbonate in LiPF6-based electrolytes for lithium ion batteries. Electrochim. Acta 225, 358-368 (2017).

37. Han, J.-G., Kim, K., Lee, Y. \& Choi, N.-S. Scavenging materials to stabilize LiPF6-containing carbonate-based electrolytes for Li-ion batteries. $A d v$. Mater. 31, 1804822 (2019).

38. Alvarado, J. et al. Bisalt ether electrolytes: a pathway towards lithium metal batteries with Ni-rich cathodes. Energy Environ. Sci. 12, 780-794 (2019).

39. Olivato, P. R., Guerrero, S. A., Yreijo, M. H., Rittner, R. \& Tormena, C. F. Conformational and electronic interaction studies of 2-fluoro-substituted $\mathrm{N}$, N-dimethylacetamides. J. Mol. Struct. 607, 87-99 (2002).

40. Li, N.-W. et al. A flexible solid electrolyte interphase layer for long-life lithium metal anodes. Angew. Chem. Int. Ed. 57, 1505-1509 (2018).

41. Jiao, S. et al. Behavior of lithium metal anodes under various capacity utilization and high current density in lithium metal batteries. Joule 2, 110-124 (2018).

42. Ensling, D., Stjerndahl, M., Nytén, A., Gustafsson, T. \& Thomas, J. O. A comparative XPS surface study of Li2FeSiO4/C cycled with LiTFSI- and LiPF6-based electrolytes. J. Mater. Chem. 19, 82-88 (2009).

43. Leroy, S., Martinez, H., Dedryvère, R., Lemordant, D. \& Gonbeau, D. Influence of the lithium salt nature over the surface film formation on a graphite electrode in Li-ion batteries: an XPS study. Appl. Surf. Sci. 253, 4895-4905 (2007).

44. Song, J.-H. et al. Effect of fluoroethylene carbonate on electrochemical performances of lithium electrodes and lithium-sulfur batteries. $J$. Electrochem. Soc. 160, A873-A881 (2013). 
45. Zhang, X.-Q., Cheng, X.-B., Chen, X., Yan, C. \& Zhang, Q. Fluoroethylene carbonate additives to render uniform Li deposits in lithium metal batteries. Adv. Funct. Mater. 27, 1605989 (2017).

46. Yan, C. et al. Lithium nitrate solvation chemistry in carbonate electrolyte sustains high-voltage lithium metal batteries. Angew. Chem. Int. Ed. 130, 14251-14255 (2018).

47. Zhang, A., Fang, X., Shen, C., Liu, Y. \& Zhou, C. A carbon nanofiber network for stable lithium metal anodes with high Coulombic efficiency and long cycle life. Nano Res. 9, 3428-3436 (2016).

48. Jolly, W. L., Bomben, K. D. \& Eyermann, C. J. Core-electron binding energies for gaseous atoms and molecules. At. Data Nucl. Data 31, 433-493 (1984).

49. Lv, S. et al. Operando monitoring the lithium spatial distribution of lithium metal anodes. Nat. Commun. 9, 2152 (2018).

50. Han, F. et al. High electronic conductivity as the origin of lithium dendrite formation within solid electrolytes. Nat. Energy 4, 187-196 (2019).

51. Lee, S. H., Hwang, J.-Y., Park, S.-J., Park, G.-T. \& Sun, Y.-K. Adiponitrile (C6H8N2): a new bi-functional additive for high-performance Li-metal batteries. Adv. Funct. Mater. 0, 1902496 (2019).

52. Kim, J. et al. Prospect and reality of Ni-rich cathode for commercialization. Adv. Energy Mater. 8, 1702028 (2018).

53. Pang, Q., Liang, X., Shyamsunder, A. \& Nazar, L. F. An in vivo formed solid electrolyte surface layer enables stable plating of Li metal. Joule 1, 871-886 (2017).

54. Li, J. et al. The impact of electrolyte additives and upper cut-off voltage on the formation of a rocksalt surface layer in LiNi0.8Mn0.1Co0.1O2 electrodes. J. Electrochem. Soc. 164, A655-A665 (2017).

55. Li, S. et al. Compatibility between lithium difluoro (oxalate) borate-based electrolytes and $\mathrm{Li1} .2 \mathrm{Mn} 0.54 \mathrm{Ni} 0.13 \mathrm{Co} 0.13 \mathrm{O} 2$ cathode for lithium-ion batteries. J. Electroanal. Chem. 823, 688-696 (2018).

56. Ziegler, J. F., Ziegler, M. D. \& Biersack, J. P. SRIM The stopping and range of ions in matter (2010). Nucl. Instrum. Methods Phys. Res. Sect. B Beam Interact. Mater. Atoms 268, 1818-1823 (2010).

57. Zhang, X., Verhallen, T. W., Labohm, F. \& Wagemaker, M. Direct observation of Li-ion transport in electrodes under nonequilibrium conditions using neutron depth profiling. Adv. Energy Mater. 5, 1500498 (2015).

58. Lee, C., Yang, W. \& Parr, R. G. Development of the Colle-Salvetti correlationenergy formula into a functional of the electron density. Phy. Rev. B 37, 785-789 (1988).

59. Boys, S. F. \& Bernardi, F. The calculation of small molecular interactions by the differences of separate total energies. Some procedures with reduced errors. Mol. Phy. 100, 65-73 (2002).

60. Frisch, M. J. et al. Gaussian 09 (Gaussian, Inc., Wallingford, CT, 2010).

\section{Acknowledgements}

The research leading to these results has received funding from National Nature Science Foundation of China (No. 51872157), Shenzhen Technical Plan Project (No. JCYJ20170817161753629, KQJSCX20160226191136, JCYJ20170412170911187, ZDSYS211707271615073), Guangdong Technical Plan Project (No. 2015TX01N011), Special Fund Project for Strategic Emerging Industry Development of Shenzhen
(20170428145209110), Local Innovative and Research Teams Project of Guangdong Pearl River Talents Program (2017BT01N111), Computations were performed on the Niagara supercomputer at the SciNet HPC Consortium. SciNet is funded by: the Canada Foundation for Innovation; the Government of Ontario, Ontario Research FundResearch Excellence, and the University of Toronto, and the Netherlands Organization for Scientific Research (NWO) under the VICI grant no. 16122.

\section{Author contributions}

M.W. and B.L. supervised the research, C.Z., Y.H., and F.K. advised during the research. Q.W. designed and performed the experiments. Z.Y., D.P., and A.A. performed DFT calculations. T.V., M.L., and F.O. developed the NDP analysis and interpreted the NDP data with Q.W. and M.W., Q.W. and M.W. prepared this manuscript with inputs from all other co-authors. All authors participated in analyzing the experimental results and preparing the manuscript.

\section{Competing interests}

The authors declare no competing interests.

\section{Additional information}

Supplementary information is available for this paper at https://doi.org/10.1038/s41467020-17976-x.

Correspondence and requests for materials should be addressed to M.W. or B.L.

Peer review information Nature Communications thanks Hailiang Wang, and the other, anonymous, reviewer(s) for their contribution to the peer review of this work.

Reprints and permission information is available at http://www.nature.com/reprints

Publisher's note Springer Nature remains neutral with regard to jurisdictional claims in published maps and institutional affiliations.

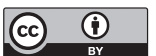

Open Access This article is licensed under a Creative Commons Attribution 4.0 International License, which permits use, sharing, adaptation, distribution and reproduction in any medium or format, as long as you give appropriate credit to the original author(s) and the source, provide a link to the Creative Commons license, and indicate if changes were made. The images or other third party material in this article are included in the article's Creative Commons license, unless indicated otherwise in a credit line to the material. If material is not included in the article's Creative Commons license and your intended use is not permitted by statutory regulation or exceeds the permitted use, you will need to obtain permission directly from the copyright holder. To view a copy of this license, visit http://creativecommons.org/ licenses/by/4.0/.

(C) The Author(s) 2020 